\title{
Publisher Correction: Five decades of eukaryotic transcription
}

Correction to: Nature Structural \& Molecular Biology https://doi.org/10.1038/s41594-019-0303-1, published online 26 August 2019.

In the version of this article initially published, several of the links were incorrect. The correct links are as follows: Roeder, https://doi.org/10.1038/s41594-019-0287-x; Kadonaga, https://doi.org/10.1038/s41594-019-0278-y; Conaway and Conaway, https://doi. org/10.1038/s41594-019-0283-1; and Lis, https://doi.org/10.1038/s41594-019-0288-9. The errors have been corrected in the HTML and PDF versions of the article.

Published online: 4 November 2019

https://doi.org/10.1038/s41594-019-0338-3

() Springer Nature America, Inc. 2019

\section{Publisher Correction: Targeting chromatin}

Correction to: Nature Structural \& Molecular Biology https://doi.org/10.1038/s41594-019-0315-x, published online 3 October 2019.

In the version of this article initially published, several of the links were incorrect. The correct links are as follows: Husmann and Gozani, https://doi.org/10.1038/s41594-019-0298-7; Zaware and Zhou, https://doi.org/10.1038/s41594-019-0309-8; Arrowsmith and Schapira, https://doi.org/10.1038/s41594-019-0290-2; Tzelepis, Rausch and Kouzarides, https://doi.org/10.1038/s41594-019-0312-0; and Noberini and Bonaldi, https://doi.org/10.1038/s41594-019-0279-x. The errors have been corrected in the HTML and PDF versions of the article.

Published online: 4 November 2019

https://doi.org/10.1038/s41594-019-0336-5

(c) Springer Nature America, Inc. 2019 